\title{
IDENTIDADES EN EMERGENCIA: LA OTRA CARA DE LA RECONSTRUCCIÓN. EL CASO DE CHAITÉN
}

\author{
CATALINA ARTEAGA A. ${ }^{a} \&$ ANA M. UGARTE C. ${ }^{b}$
}

\begin{abstract}
RESUMEN
Los desastres naturales son eventos que generan grandes cambios en las sociedades en las cuales ocurren. Uno de los efectos sociales de los desastres naturales sobre la población es la transformación del proceso a través del cual los sujetos se vinculan consigo mismos y con el grupo social al que pertenecen. En un contexto tal de vulnerabilidad y riesgo social, donde el territorio y la cotidianidad cambian drásticamente, la construcción del sentido de pertenencia se dificulta, pues los referentes clásicos de identidad personal y colectiva de los sujetos sufren alteraciones. En este contexto emergen nuevas formas de constitución del sí mismo, nuevos símbolos, espacios y recursos desde donde se perciben, construyen y negocian las identidades. Como señalan distintos autores, los procesos de construcción de identidad son relevantes de analizar, en la medida que delimitan las fronteras individuales y colectivas; posibilitan la relación con otros; constituyen un sustrato para la acción.

En este artículo se discute el impacto de los desastres socionaturales en la construcción de identidad personal y colectiva en sujetos y comunidades que los enfrentan, particularmente, desde el análisis del caso de Chaitén -ciudad al sur de Chile- que fue azotada por una erupción volcánica y una gran inundación el año 2008, y que hasta el día de hoy sigue en proceso de reconstrucción. A través del uso de metodologías cualitativas desde el enfoque de la teoría fundamentada, se analizan los cambios, tránsitos y fricciones en los referentes identitarios de los chaiteninos, a partir de la experiencia del desastre, así como las formas en las cuales éstos influyen en la imagen de ciudad y territorio que la población construye actualmente; las modalidades de construcción del nosotros, así como en las transformaciones de sus expectativas y proyectos de vida.
\end{abstract}

PALABRAS CLAVE: Desastres Socionaturales, identidad, territorio, vulnerabilidad. 


\title{
IDENTITIES IN EMERGENCY: THE OTHER SIDE OF THE RECONSTRUCTION. THE CASE OF CHAITÉN
}

\begin{abstract}
Natural disasters are events that generate large changes in the societies in which they happen. One of the social impacts of natural disasters on the population is the change in the process through which subjects are linked with themselves and with the social group to which they belong. In such contexts of vulnerability and social risk where the territory and daily life changes dramatically, building a sense of belonging is difficult, because the classic references of personal and collective identity of the subjects suffer alterations. In contexts like these, new forms of self- constitution emerge; the identities are negotiated and constructed from new symbols, spaces and resources. Several authors notice that the processes of identity construction are relevant to analyze, because they allow demarcating individual and collective borders; making possible relationship with others; constituting a substrate for action.

This article discusses the impact of socio-natural disasters in the construction of personal and collective identity in individuals and communities, particularly from a case study: Chaitén, city of Chile which was hit by a volcanic eruption and a great flood on 2008, and until today still under reconstruction. Using qualitative methods from the grounded theory approach, it analyzes changes, transitions and frictions in the identity's references. Also, it analyzes the ways in which this references influence the image of city and territory that population build actually and how the population construct a sense of us. Finally; it discusses about transformations of population's expectations and lifestyles.
\end{abstract}

KEY WORDS: Socio Natural Disasters, identity, territory, vulnerability.

\section{INTRODUCCIÓN}

El impacto de los desastres naturales en la población ha sido analizado desde distintas perspectivas en los estudios sobre las catástrofes naturales en el mundo. Una línea de análisis ahonda en las vulnerabilidades preexistentes de las poblaciones impactadas por estos eventos, las cuales coexistirian entre los factores que producen mayores o menores impactos en las poblaciones afectadas. Ello permitiría comprender, de alguna manera, el impacto diferenciado de los desastres en la población que los vive. Como indica Revet (2011), el uso de la noción de vulnerabilidad en los estudios de desastres, subraya las condiciones que se producen en una sociedad particular y que favorecen la transformación de un desastre natural en una catástrofe. Otra vertiente de estudios ha analizado el impacto y la mayor precarización de las comunidades afectadas por los hechos, centrando la descripción en el aumento de la vulnerabilidad de las zonas impactadas por desastres y sus comunidades (Weichselgartner, 2001). Estas perspectivas se inscriben en los estudios que analizan los desastres naturales desde una mirada compleja, que entiende la ocurrencia y consecuencias de los desastres desde una perspectiva física, pero que además busca analizar los elementos sociales que inciden en que los desastres ocurran y en las modalidades en que las poblaciones son mayor o menormente afectadas; las maneras en que éstas lo son y las acciones y estrategias que los sujetos y las instituciones hacen frente a estas emergencias. Desde estas perspectivas, podemos referirnos a desastres socionaturales, entendiendo que en la ocurrencia del impacto y el proceso posterior al evento natural propiamente tal, inciden una serie de factores ambientales, sociales y psicológicos que permiten comprender de mejor manera las diversas consecuencias de los desastres en las poblaciones afectadas. En este sentido, se cuestiona la idea de que los desastres sean meramente fenómenos naturales (Maskrey, 1993).

Dentro del análisis de los impactos de los desastres, algunos estudios han puesto énfasis en las consecuencias económicas (Cardona, 2001; Meli et al. 2005; CEPAL, 2010), políticas (Letelier \& Boyco, 2010) y sociales (Wilches-Chaux, 1993; Cutter et al. 2003) de la ocurrencia de erupciones volcánicas, inundaciones, tsunamis, terremotos 
y huracanes. En este caso, el presente artículo busca indagar en la relación entre la ocurrencia del desastre en la localidad de Chaitén ocurrido en el año 2008 -erupción volcánica y desborde del río Blanco-y el proceso de construcción de identidades de la población de dicha localidad, ahondando específicamente, en las identidades individuales y colectivas. A partir del trabajo llevado a cabo en la comunidad por parte del equipo del Centro de Investigación en Vulnerabilidades y Desastres Socionaturales (CIVDES) de la Universidad de Chile $^{1}$, planteamos en este caso que la ocurrencia de la erupción volcánica y el desborde del río principal de la ciudad, así como el proceso de evacuación ordenado por las autoridades, la relocalización de las/os chaiteninos en distintas ciudades y localidades del continente y posteriormente el proceso de regreso y reconstrucción, incidieron en una revalorización de referentes históricos, socioculturales y territoriales del ser Chaitenino/a, a la vez que en un reforzamiento de una identidad política vinculada al territorio, en contraposición al gobierno. Desde la perspectiva de los sujetos, el desastre produjo algunas consecuencias contradictorias: la crisis en los referentes tradicionales y la reconstrucción identitaria en base a elementos complementarios o novedosos a los tradicionales.

El texto desarrollará un primer apartado que contextualiza el caso de Chaitén y presenta la metodología del estudio. Posteriormente se aborda la relación entre desastres y construcción identitaria, para posteriormente dar paso a los resultados centrados en las modalidades de construcción colectiva $e$ individual que se despliegan a partir de la erupción volcánica y el proceso posterior de evacuación y retorno de la población.

\section{DESCRIPCIÓN DEL CASO: CHAITÉN}

El 02 de Mayo de 2008 hace erupción el

1 Núcleo Milenio en Ciencias Sociales, financiado por la Iniciativa Científica Milenio dependiente del Ministerio de Economía, Fomento y Turismo (Proyecto NS 100022).

2 Periodo de tiempo contemplado entre la erupción del volcán y los primeros tres meses posteriores a ésta (Marchant, 2010).

3 Periodo de tiempo contemplado entre los 3 meses posteriores a la emergencia y el retorno masivo de la población a Chaitén, a fines del año 2010, tras la
Volcán Chaitén, ubicado en la ciudad de Chaitén, Región de Los Lagos, Sur de Chile. Una de sus múltiples consecuencias fue la inundación de la ciudad por el desborde del Río Blanco, a causa de la saturación de su cauce por las cenizas; lo que implicó que la ciudad se dividiera en dos espacios geográficos: el norte y el sur, puesto que el río, al desbordarse, atravesó la zona de oriente a poniente, formando un nuevo cause que arrasó con la ciudad.

Ante esta situación, el Estado emprendió diferentes acciones de gestión del riesgo. En un primer momento -el de la emergencia- ${ }^{2}$, se designó una Delegación Presidencial especialmente para este caso, la que se hizo cargo de responder ante el desastre coordinándose con la Oficina Nacional de Emergencias (ONEMI) ${ }^{3}$ y distintos Ministerios. Estas autoridades decidieron evacuar por completo la ciudad, trasladando a un total de 4.700 personas desde Chaitén hacia distintos destinos principalmente ubicados en el sur del país, como Puerto Montt, Chiloé y Futaleufú, entre otros (ONEMI, 2008a, 2008b; Marchant, 2010), ubicando a las personas en albergues temporales (durante 2 meses), dándoles un bono por la emergencia y apoyo en alimentación y vestuario.

Posteriormente, durante la etapa de desplazamiento ${ }^{4}$ de la población, el Gobierno (durante el año 2008) declaró la ciudad de Chaitén como inhabitable por ser alto el riesgo de un nuevo desastre natural. Esto implicó orientar las acciones del Estado hacia quienes quedaron en calidad de desplazados, acciones que consistieron principalmente en bonos de manutención y un subsidio para la vivienda (Marchant, 2010), junto con la oferta de compra de las casas de los chaiteninos, al mismo precio avaluado antes del desastre (Ministerio Bienes Nacionales, 2009 en Ugarte, 2014) y con la oferta de apoyo psicosocial (atención psicológica y capacitación laboral). Durante este periodo, el Gobierno anunció la

declaración de habitabilidad de la zona. Cabe señalar que actualmente aún existen varias unidades familiares en calidad de desplazadas.

4 Periodo de tiempo contemplado entre los 3 meses posteriores a la emergencia y el retorno masivo de la población a Chaitén, a fines del año 2010, tras la declaración de habitabilidad de la zona. Cabe señalar que actualmente aún existen varias unidades familiares en calidad de desplazadas. 
creación de una nueva ciudad para los chaiteninos, el Proyecto Santa Bárbara5; sin embargo, esta nunca se concreta y en abril de 2010, la nueva Administración ${ }^{6}$ anunció oficialmente que las personas podían retornar al sector norte de Chaitén (Marchant, 2010).

Tras esta declaración de habitabilidad de Chaitén y posibilidad de retorno para la población desplazada, el Gobierno Central se retiró de la gestión del riesgo y apareció fuertemente el Gobierno Local (Gobernación Regional y Servicios Municipales), el cual llevó a cabo acciones que consistieron básicamente en administrar viviendas para el retorno; otorgar orientación a la comunidad, proveer servicios básicos (luz, agua, alcantarillado), otorgar acceso a la escuela (bus de acercamiento) y reparar algunas casas de los daños ocasionados por las cenizas.

Dentro de los principales impactos que este desastre tuvo en la población, se pueden señalar los siguientes: destrucción total de la ciudad; división de la zona en dos espacios geográficos diferentes, con escasa conexión entre ellos; desarticulación, tanto en lo público como en lo privado, de los distintos sistemas sociales y vínculos cotidianos establecidos entre las personas y comunidades; pérdidas de empleos; cambios en la composición de la unidad familiar; problemas de salud mental, como depresión y estrés post traumático; entre otros (Marchant, 2010; Ugarte, 2014). Además de lo señalado, el impacto del desastre se manifestó, al mismo tiempo, en la relación que estableció la comunidad con el territorio; impactos que, en función de las distintas etapas del desastre, se tradujeron en sentimientos de desarraigo e incertidumbre. Por otra parte, las transformaciones territoriales, como la división entre Chaitén norte y Chaitén sur, se convirtieron en elementos centrales en los procesos actuales de construcción de identidad colectiva, dando paso a procesos de significación inter-subjetiva entre los habitantes del nuevo

5 Este proyecto, ideado por las anteriores autoridades del Ministerio de Vivienda y Urbanismo de Chile, se erigía como una idea de ciudad modelo para 5.000 habitantes, segura, ambiental y económicamente sustentable; a sólo 10 $\mathrm{km}$ de Chaitén. Sin embargo, por el alto costo de inversión, estimado en unos US\$ 300 millones, el proyecto fue desechado por la Administración de Piñera (Neira, 2010 en territorio.

\section{METODOLOGÍA}

Para producir la información necesaria que permitiese desarrollar el análisis, utilizamos estrategias cualitativas; específicamente, trabajamos con una muestra de veinte habitantes que han retornado a Chaitén. La producción de información se realizó a través de entrevistas en profundidad individuales y grupales. Cabe señalar que la muestra fue de tipo estructural (Mejía, 2000), por lo tanto, su representatividad no alude a una representación proporcional, sino a una representación de posiciones discursivas. Es importante mencionar además que toda la muestra pertenece al área urbana de la comuna; por lo cual la información obtenida rescata el discurso respecto a las principales percepciones, sentidos y acciones que tienen lugar en este sector, el cual, si bien no fue el único impactado por el desastre, ha sido considerado como un punto de partida necesario para abordar las problemáticas socio-territoriales visibilizadas luego de la erupción y tras el retorno.

Posteriormente, luego de transcribir las entrevistas, analizamos la información producida con herramientas de la teoría fundada, a nivel de codificación abierta y relacional, utilizando el software ATLAS.ti. Lo anterior permitió generar análisis descriptivos y relacionales de los textos producidos, organizando la información a través de la elaboración y la reflexión de conceptos y categorías (Murcia \& Jaramillo, 2000), que permiten identificar y clasificar conceptualmente un conjunto de datos, examinándolos con el fin de definir ejes temáticos que ayuden a clasificar el contenido de dichas unidades de análisis, para posteriormente relacionar estas categorías entre sî destacando ejes centrales del discurso, enlazando las categorías en cuanto a sus propiedades y dimensiones (Strauss \& Corbin, 2002).

A partir del análisis, organizamos la información en base a las preguntas planteadas y

Ugarte, 2014).

6 El abordaje de la problemática de Chaitén entre 2008 e inicios de 2010 se realiza en la Administración de Michelle Bachelet; luego, quien continúa el trabajo es la Administración del presidente Sebastián Piñera, quien asume el gobierno del país en marzo de 2010. 
los ejes emergidos de los relatos.

\section{CONSTRUCCIÓN DE IDENTIDADES Y DESASTRES SOCIONATURALES}

Como ha sido señalado por distintos autores, la identidad no es una esencia, un atributo o una propiedad intrínseca del sujeto, sino que tiene un carácter intersubjetivo y relacional...la identidad de un actor social emerge y se afirma sólo en la confrontación con otras identidades en el proceso de interacción social... (Giménez, 2000, p. 50). Como elementos diferenciadores de una identidad, Giménez destaca: la pertenencia a una pluralidad de colectivos; la presencia de atributos idiosincráticos o relacionales y una narrativa biográfica que recoge la historia de vida y la trayectoria social de la persona considerada.

Dentro de la pertenencia, ella se lleva a cabo generalmente a partir de la apropiación $e$ interiorización al menos parcial del complejo simbólico-cultural que funge como emblema de la colectividad en cuestión (Giménez, 2000, p. 52), en este marco, ...pertenecer a un grupo o una comunidad implica compartir el núcleo de representaciones sociales que los define y caracteriza (Ibíd., p. 54), las cuales son un conjunto de construcciones sociocognitivas propias del pensamiento ingenuo o del sentido común, que pueden definirse como conjunto de informaciones, creencias, opiniones y actitudes a propósito de un objeto determinado (Abric, 1994 en Giménez, 2000, p. 54). Así las personas ven las cosas desde el punto de vista de su grupo de pertenencia o de referencia (Giménez, 2000, p. 55).

La perspectiva de las identidades como un proceso de construcción social, conlleva asimismo la idea de la relación dinámica y cambiante que ésta puede tener. Al estar en vínculo con procesos sociales más amplios, las transformaciones y complejidades del entorno, pueden suponer ajustes, modificaciones y eventualmente cambios en la construcción identitaria (Valenzuela, 2000; Berger \& Luckmann, 1999). En dicho marco, la ocurrencia de eventos socionaturales como terremotos, erupciones volcánicas, inundaciones, puede incidir en las modalidades de constitución de identidades individuales y colectivas. En efecto, la relación entre construcción de identidades individuales y colectivas y desastres socionaturales, puede analizarse desde distintas perspectivas, en la medida que el evento físico y sus consecuencias en distintas dimensiones a lo largo del tiempo, inciden en las modalidades de su construcción. Al respecto, podemos señalar tres elementos que nos parecen centrales de dicho vínculo:

a. La ocurrencia de los desastres pone en suspenso las rutinas, certezas y ritmos de la vida cotidiana.

Retomando a Berger y Luckmann (1999) planteamos que las identidades sociales requieren, en primera instancia y como condición de posibilidad, de contextos de interacción estables, constituidos en forma de 'mundos familiares' de la vida ordinaria. Este mundo de la vida proporciona a los sujetos un marco a la vez cognitivo y normativo capaz de orientar y organizar interactivamente sus actividades ordinarias (Dressler, 1986 en Giménez, 2000, p. 68). Sin embargo, ante la ocurrencia de estos eventos y sus consecuencias, generalmente se alteran las rutinas, certezas y referentes materiales y simbólicos que dotan de coherencia y estabilidad las dinámicas cotidianas de la población.

b. En situaciones de desastres, la relación al interior de las comunidades, así como con otros actores a nivel local, regional o nacional, enfatiza la puesta en escena y la disputa en torno a componentes simbólicos, creencias, opiniones y estrategias diversas, lo que pone en tensión las identidades colectivas.

Las prácticas organizativas desplegadas en las localidades con el objeto de enfrentar y resolver los problemas que surgen a partir del desastre, refuerzan en ocasiones el sentido de comunidad y muchas veces son posibilitadas por el capital social preexistente, sin embargo, también pueden generar situaciones de conflicto y diferenciación al interior de la población por el acceso a recursos y beneficios. Dichos conflictos, asimismo, pueden darse en la relación con las instancias gubernamentales de los distintos 
niveles, a partir de las distancias entre las orientaciones de las políticas públicas y las necesidades de la población.

c. En contextos de desastre, los sujetos y las colectividades involucradas, ponen con mayor énfasis en evidencia para sí mismos y los otros, creencias, valores y opiniones respecto a lo que han sido, son y esperan ser.

Dicha reflexividad da cuenta de procesos de análisis individuales y colectivos acerca del sí mismo, el colectivo, las comunidades, el pasado, el presente y el futuro. En ese marco, los individuos, las familias, las comunidades, despliegan reflexiones acerca de elementos que son valorados como referentes en la construcción de sus identidades en los distintos niveles, lo que puede implicar reordenamientos en las expectativas, objetivos y sentidos de la construcción individual y colectiva.

A continuación analizaremos algunos de estos aspectos en el caso de Chaitén, indagando en la construcción de las identidades individuales $y$ colectivas en el contexto del desastre. Específicamente abordaremos el tema de los referentes en la construcción de las identidades grupales; la constitución de una identidad política y los impactos en términos de las identidades individuales.

\section{ANÁLISIS DE RESULTADOS}

\section{Referentes Identitarios en los Chaiteninos}

A partir de la erupción volcánica, desborde del río y evacuación de la población, pudimos constatar en los relatos, el énfasis que se establece en algunos referentes identitarios relacionados con la historia y la trayectoria del pueblo, aludiendo a elementos vinculados al poblamiento originario de Chaitén. Los principales referentes identitarios para la población chaitenina, que forman la base de una fuerte identidad colectiva, se relacionan con la diversidad; con el esfuerzo y la lucha; con la solidaridad; con la tranquilidad y la libertad; con la naturaleza; con la incertidumbre; con la capacidad de adaptación. A continuación se describe cada una de estas dimensiones y se reflexiona acerca del sentido que estos elementos tienen en el proceso de retorno y reconstrucción de la ciudad tras el desastre.

La diversidad como referente identitario en los chaiteninos se basa en los orígenes de la ciudad. Chaitén fue fundada en 1933, como estrategia gubernamental para poblar las zonas australes del país y ejercer soberanía territorial. La ciudad fue construida por los mismos colonos, personas procedentes de la isla de Chiloé, de Temuco, de Villarrica, de Puerto Montt, de Futaleufú y de la frontera con Argentina, que se aventuraron a habitar este desconocido territorio. Esta variedad de culturas y costumbres de los colonos es un elemento que para los chaiteninos se valora positivamente como elemento de identidad.

Es que Chaitén se pobló desde Chiloé y desde la frontera con Argentina. Entonces vinieron de todos lados. Chaitén se caracteriza, su identidad para mi era justamente la diversidad, porque éramos gente venidas de todos lados, especialmente chilotes, mucha costumbre chilota, tanto en el aspecto de la construcción como de costumbres del diario vivir (Entrevista Docente Escuela).

Inicialmente los colonos se instalaron en los valles cercanos a los ríos cordilleranos (río Yelcho y río Futaleufú); sin embargo, a los pocos años decidieron poblar más hacia el poniente, hacia la costa del territorio, puesto que la zona cordillerana no reunía las características para formar una ciudad (ríos muy torrentosos, valles estrechos, dificultad de acceso). Si bien el lugar donde finalmente se establecen los colonos también presenta dificultades geográficas, imponiendo mucho esfuerzo para instalarse en la zona, tras años de perseverancia logra crecer el pueblo, el que inicialmente emerge como poblado rural, y luego llega a convertirse en ciudad y posteriormente, en capital provincial (de la Provincia de Palena). El esfuerzo que requiere habitar un espacio geográfico hostil y levantar una ciudad en medio de la nada, es entonces otro referente de identidad de los chaiteninos. Ellos se miran a sí mismos como los soberanos del territorio, por haberlo construido a pesar de toda 
adversidad:

Toda la gente aqui es esforzada para vivir. Ahora más o menos a estas alturas ya no tanto, pero años atrás era fuerte vivir acá. No era fácil. Nuestros abuelos fueron los que hicieron esto. No fue el Estado chileno, porque nunca el Estado chileno ha estado en las zonas australes, son los colonos que llegaron a hacer patria, a pesar de todo, y aqui se quedaron (Entrevista Dirigente Social $1)$.

Otro referente importante de identidad para los chaiteninos se relaciona con la solidaridad, la cual emergió nuevamente ante la situación de desastre; la población se concibe con un fuerte sentimiento de unidad orientado a intereses comunes; es decir, son capaces de compartir entre ellos, de entregarse ante una causa común, y que por ende constantemente se ayudan entre sí, aún más en situaciones de vulnerabilidad como aquella que generó el desastre socionatural:

De hecho nadie pensó en forma personal. Por ejemplo, ésta no es mi casa, es de una persona que al momento en que yo iba a volver, luego de tres meses de la erupción, me dijo: Aquí está la llave, si la quieres ocupar, si te sirve úsala (Entrevista Dirigente Social 2).

Y mientras transcurría todo el tema, mira a esta casa le llamaban el Hogar de Cristo, ni el dueño de casa había tenido tanta gente en toda su vida que vivió aquí. El que llegaba a pedir ayuda tenía donde dormir, había baño, había agua, luz (autogenerada); porque no le podiamos decir que no si uno sabía que era un caso de heridos. Uno abría todas las puertas y así mucha gente se instaló acá con nosotros (Entrevista Grupal 2).

Ante la evacuación y la valorización del territorio, emerge con fuerza en el discurso la tranquilidad y la libertad como referentes identitarios, que implican para los chaiteninos además una valoración altamente positiva de su calidad de vida. Sostienen que Chaitén es una ciudad donde se puede transitar sin apuros, sin preocupaciones, donde todos se conocen y se cuidan, donde existe confianza, no hay temor al daño ni a la violencia. Los chaiteninos se sientes felices y seguros en su pueblo y eso para ellos configura una experiencia de buena calidad de vida, pues relevan los elementos vinculados a redes de apoyo social y a salud mental. Para ellos, esta calidad de vida es inigualable; es decir, no se halla en otros lugares. Este último punto se refuerza cuando tras la evacuación deben vivir en otras ciudades, que tienen ritmos de vida muy distintos a los existentes en Chaitén:

Entonces a mi me gusta vivir en una localidad más tranquila, más apacible, donde todos nos conocemos, uno va por la calle y se saluda con todo el mundo, donde de repente va al negocio y si se le queda la plata en la casa le van a vender igual porque saben que al día siguiente la persona va a ir a pagar, sabe que su hijo sabe del kinder a las 5 de la tarde cuando está oscuro y nadie le va a hacer nada, que nadie lo va a agredir, que puede salir de su casa dejando las puertas sin llave y que nadie va a ingresar. Entonces uno empieza a valorar es estilo de vida y ese es otro factor que para nosotros fue muy importante, lo que nosotros denominamos el estilo, la forma de vida que nosotros teníamos acá. Muchos no queríamos perder eso. Tenemos una vida tranquila y sobre todo los pequeños... a mí me interesa que mi hijo crezca en un lugar donde uno esté pendiente que le vaya a pasar algo o todos los problemas de bullying que uno escucha todos los días en las noticias (Entrevista Apoderado Escuela).

Acá tienes certeza, cierta seguridad en el tránsito, cachai, cosas que no están en las ciudades grandes donde están desplazados los de Chaitén. Entonces esas cosas, tienen que ver con, con...calidad de vida en definitiva, qué tipo de educación recibes, qué tipo de salud recibes, probablemente acá tenías una salud restringida, pero tenías una salud cercana, casi de carácter personal la relación. Pero afuera tú tienes que esperar. Allá todo es un tema estresante (Entrevista 
Representante Gobierno Local 2).

Muy relacionado con lo anterior aparece una valoración del referente vinculado a la naturaleza. Para los chaiteninos es muy importante vivir cerca del mar, en contacto con los bosques, con los ríos, con el mar; con su entorno natural. La presencia de la naturaleza en la vida de los chaiteninos los marca fuertemente, ellos han nacido y se han criado en un entorno con estas características y trasladarse a lugares donde no tienen contacto con este elemento les angustia y deprime.

Acá uno respira un aire puro limpio, disfruta de una naturaleza pero espectacular, acá adentro del pueblo cuando usted sale afuera por ahí por El Amarrillo, no sé, la carretera para arriba para camino a Futaleufú es impresionante en tiempo de verano lo hermoso que es, entonces son todas esas cosas que uno es imposible cambiarlo con una ciudad pues oiga (Entrevista Comerciante).

¡Ay! yo adoro todos los árboles, los amo, yo me levanto en la mañana y lo primero que miro el cerro, y siempre cuando estaba en puerto Montt, soñaba que yo estaba arriba como un alto y que había una puerta, y que yo miraba y era como que yo estaba en la gruta, de la gruta yo miraba hacia acá y veía Chaitén, pero no como está ahora, como estaba antes, y yo siempre decía: "algún día voy a volver", porque siempre como que estaba mi mente acá, y... y lo que más amo el mar, y el río, el río lo adoro (Entrevista Apoderada Escuela).

Cambios a partir del desastre:

incertidumbre, inseguridad, adaptación

Como señalamos, frente a los desastres, se produce una ruptura de la dinámica cotidiana, lo que pone en suspenso las certezas del día a día. Los referentes descritos anteriormente se relacionan con elementos de identidad que se han ido configurando durante años de relación con el entorno y entre quienes lo habitan; sin embargo, actualmente también aparecen otros elementos identitarios que marcan la construcción que hoy realizan de sí mismos los chaiteninos y que emergen tras la experiencia de vivir el desastre. Estos nuevos referentes identitarios son la incertidumbre, la inseguridad como experiencia de vulnerabilidad, y la capacidad adaptación como estrategia de sobrevivencia.

La incertidumbre y la inseguridad se expresan en la vida de los chaiteninos como sentimientos de fragilidad $e$ indefensión ante cambios originados en el entorno, ya no sólo ante los originados por el desastre, sino que ante todo evento nuevo que enfrentan. Esto se traduce muchas veces en un sentimiento permanente que paraliza, incapacita y desmotiva la posibilidad de pensar estrategias y actuar a futuro para lograr mejores niveles de bienestar. A esto se suma el no saber si seguirán viviendo en Chaitén o no, si están en peligro, si tendrán que dejar nuevamente sus hogares. Todo ello repercute en la existencia de altas dificultades para proyectarse a futuro, es decir, construir un proyecto de vida. Cabe señalar que para los chaiteninos, el responsable de esta experiencia de vulnerabilidad a la que se enfrentan es el Estado, debido al desamparo institucional que perciben de este:

Uno va a tocar puertas por ejemplo, y las oficinas no te dan soluciones. Por ejemplo hay gente que aqui tienen subsidio, que le dieron a gente de Chaitén, y ellos lo quieren ocupar acá en Chaitén, para comprar casas aquí en Chaitén, y uno pregunta en puerto Montt, le dicen: 'ah no sé, voy a preguntar'. Pregunta en Futaleufú: 'no sé, no tengo idea. Si es realmente... va a otra oficina y le dicen: 'sí, si pueden comprar en Chaitén". Y da impotencia, da esa rabia de que no, de que nadie te pueda dar una información como corresponde, como la verdad, no andarte diciendo así 'sí, se puedé, y tú vai' a otra oficina: 'oye y quién le dijo eso si no es verdad'. Entonces ¿a quién le creo? (Entrevista Grupal 1).

Es que yo creo que en vez de que uno se vaya recuperando, esto va eh... va peor, va peor porque, eh... como le decía 'denante' uno no tiene una seguridad, si uno va a poder vivir en esa casa o no va a poder vivir, si uno va a poder seguir ahí, nosotros 
si no... no tenemos la seguridad si nos van a dejar seguir viviendo ahí, si 'de repente' nos van a sacar...uno no sabe, no sabe. No es de uno (el control). Es una incertidumbre, que estamos viviendo, el día a día, o sea todos los días estamos viviendo eso, porque uno se levanta...y uno no puede hacer nada (Entrevista Grupal 2).

Ante esta situación de incertidumbre e inseguridad que inunda el presente y tiñe el futuro, los chaiteninos utilizan la estrategia de adaptación como forma de sobrevivencia, lo que les permite continuar en Chaitén a pesar de la experiencia de vulnerabilidad social a la que se enfrentan. Identificarse con la figura del que resiste las adversidades (tal como los colonos), del que a pesar de todo sigue en pie, les ayuda a mantener y concretar planes de reconstrucción de su pueblo:

Lo que se perdió se perdió. Es triste, pero igual que ya uno se está acostumbrando a ver a la nueva vida nomas de aquí de Chaitén. Hay que adaptarse nomas si uno quiere estar acá. Tenemos que adaptarnos a lo que tenemos (Entrevista Cocineras Escuela).

Como puede observarse tras lo descrito, los referentes de identidad utilizados por los chaiteninos para definirse a sí mismos los impulsan al retorno, por una parte, y les permiten reconstruir su ciudad bajo la idea de una nueva colonización. Para los chaiteninos su pueblo es más que un lugar de residencia, es una opción de vida. Cuando tras la evacuación la ciudad fue declarada como inhabitable por el alto riesgo que presentaba para la población, un grupo de 12 chaiteninos (designados por la prensa como los rebeldes) retornó a pesar de esto, de manera ilegal, pululando primero entre lugares cercanos y sus hogares en Chaitén, ya que inicialmente los militares no les permitían estar en la ciudad mucho tiempo. Luego del retorno de estos habitantes, algunos otros más se fueron sumando en el periodo comprendido entre la primera declaración oficial de inhabitabilidad de la ciudad por parte del Gobierno (2008), y la nueva declaración que le permite a la población retornar a Chaitén oficialmente (2010). Estos ciudadanos retornaron por su cuenta, sin permiso del Gobierno, escondidos, sobreviviendo en el territorio sin servicios básicos, primero acampando, luego habitando algunas de las casas que fueron menos dañadas, acompañándose entre ellos y apoyándose para mantenerse en la que reclamaban como su ciudad.

Bueno, yo en principio dije que yo no me iba a ir, yo siempre dije que mi casa yo no la dejaba y fui uno de los primeros que me puse a limpiar mi casa. Y seguía trabajando y siempre tuve fe. Tuve fe en el de arriba de que teniamos que volver. (...) Y segui, seguí. Después ya al tiempo llegó uno, después al tiempo ya el otro. Y eso le da más fuerzas para seguir trabajando en tu casa. Y como dije, nosotros estábamos viviendo en Palena y ya llegó el tiempo en que le dije a mi señora que entreguemos el local de arriba, que estábamos arrendando en Palena y yo me vine, y empezamos, empezamos, empezamos $y$ aqui estoy. Y ha vuelto mucha, mucha gente. Y ahora ya estamos...vivos (Entrevista Grupal 2).

(...) en julio entramos nosotros, no recuerdo bien la fecha, y nosotros éramos 12. Y nos sacaban a cada rato, o sea nosotros no viviamos en Chaitén, teníamos que vivir en Santa Bárbara o en El Amarillo, en cualquier... Nosotros nos fuimos a Santa Bárbara, y no dejaban entrar, parecíamos delincuentes, éramos dueños de nuestras propias casas, pero éramos como unos delincuentes, teníamos que andar con el carnet en la mano y nos dejaban entrar a las 9 de la mañana y salíamos a las 5 de la tarde, y todos los días, a cada rato, nos molestaban los carabineros, los militares (Entrevista Dirigente Social 1).

Tan fuerte es el deseo de los chaiteninos por volver a su ciudad, que al momento de la Declaración de Habitabilidad (2010) comenzó rápidamente el retorno masivo de la población; la que actualmente cuenta con aproximadamente 2.000 habitantes (Cifra tentativa entregada por el Encargado de la Dirección de Desarrollo Social). 
La vuelta a casa, el retorno, el habitar nuevamente el espacio se significa comola verdadera vida, como aquello que les permite seguir adelante después del desastre. Volver era para ellos necesario porque estando fuera sentían mucha nostalgia de su ciudad, no lograban adaptarse a las nuevas vidas que se les ofrecen. Chaitén es diferente, para ellos, a todos los demás pueblos y ciudades; allí se vive distinto, tranquilo, en comunión con los vecinos, sin el estrés y el aislamiento de la ciudad. Chaitén es su tierra, allí nacieron, crecieron y desarrollaron sus vidas, alli estaban todos sus proyectos $y$ esperanzas, y debian proteger lo que quedaba de ella, y levantarla nuevamente. Si Chaitén nació a fuerza del hombre, en su lucha contra la naturaleza, hoy también puede volver a nacer:

Cómo me gustaría que fuera el nuevo Chaitén...Eh... yo creo que Chaitén tiene que seguir siendo Chaitén no más, yo en lo particular siento nostalgia por el Chaitén del 2008, ese Chaitén que yo vi por última vez en la gruta antes de irme un día domingo, que fui a la gruta, al mirador que está acá arriba (Entrevista Representante Gobierno Local 2).

Bengoa (1996, p. 10), sostiene que ante el temor por la pérdida de la propia identidad (...) los seres humanos, aterrorizados frente a un futuro incierto, ceden a la tentación de la mujer de sal: miran atrás, se refugian en la nostalgia (...). En este sentido, tal como señala el autor, la identidad colectiva es hija legitima de la nostalgia, se construye en torno a ella; la identidad es entonces una suma de depósitos añorados por los habitantes que miran el pasado con cierta nostalgia. De este modo, el proceso de retorno y reconstrucción encuentra justificación en la nostalgia por un estilo de vida que no se encuentra en la ciudad y que se reafirma ante el imaginario del colono, aquellos primeros pobladores que llegaron sin nada y que de todos modos lograron sobrevivir. Lo que tiene relación con lo que sostiene Orella (2010), en cuanto a que los espacios vividos cotidianamente por un grupo social que los reconoce como tales y se reconoce en pertenencia, forman parte de una extensión territorial que es apropiada por quienes lo viven, sujetos o comunidades que a su vez luchan por permanecer en estos espacios, aunque se les califique de riesgosos.

\section{Sentido de Comunidad e Identidad Colectiva}

Si bien la tendencia ante un desastre socionatural es la alteración del orden sistémico de la sociedad, lo que muchas veces implica desarticulación comunitaria, es posible que según los contextos y capacidades de respuesta de los individuos la crisis genere una re organización de los referentes identitarios de los sujetos que cuestiona la participación, el compromiso y la pertenencia al grupo. Esto puede comprenderse en mayor profundidad al analizar la organización comunitaria de un grupo humano. Para Correa y Restrepo (2000 en Ugarte, 2014), la organización comunitaria regula los vínculos entre los sujetos, representa los intereses locales, regula las distribuciones de poder, provee a la comunidad de identificación, solidaridad social y sentido de comunidad. Este último punto es importante para el análisis. A propósito, SánchezVidal (2001) señala que los elementos que le dan forma al sentido psicológico de comunidad son la percepción de similitud con otros, el reconocimiento de la interdependencia con los demás, la voluntad de mantener esa interdependencia dando o haciendo por otros lo que uno espera de ellos, y el sentimiento de que uno es parte de una estructura más amplia, estable y fiable. El sentido de comunidad entonces, se fundamenta en la interacción social entre los miembros de un colectivo, y se complementa tanto con la percepción de arraigo territorial, como con el sentimiento general de mutualidad e interdependencia:

Entonces el poder regresar acá ha sido un momento muy grato, sentirme bien, tener qué hacer, vivir en un pueblo donde la gente me conoce y yo conozco a la gente. Poderme encontrar con alguien en la calle, conversar con ellos, a lo mejor a la mitad de la calle cosa que no lo puedo hacer en una ciudad, yo me doy el lujo de caminar en la mitad de la calle acá porque eso no lo podía hacer en ninguna parte (Entrevista Grupal 1).

Esta interacción social entre los miembros de la comunidad, en relación al contexto particular vivido, va definiendo el sí mismo de cada individuo, 
otorgando sentido a las distintas situaciones en la vida cotidiana y en experiencias de más largo plazo, permite la construcción de identidad colectiva. Se habla de identidad colectiva cuando el proceso de construcción identitaria, la capacidad de definirse a sí mismo y a su ambiente, permite que los individuos sean capaces de construir expectativas comunes, en función de la realidad que viven y de su estructura de oportunidades (Melucci, 1989 en Tejerina, 2005). Así, la identidad colectiva es una definición interactiva y compartida, producida por varios individuos que interactúan y que hace referencia tanto a las orientaciones como al ámbito de oportunidades y restricciones en el que tiene lugar su acción (Melucci, 1989, p. 34 en Tejerina, 2005, p. 80). Es un continuo proceso de hacerse y rehacerse, de definirse y redefinirse, por lo que la identidad colectiva está en constante transformación.

A partir del desastre y la experiencia vivida, es posible apreciar en el discurso de los chaiteninos la construcción de una identidad colectiva según la propuesta de Melucci, vinculada al planteamiento de metas y objetivos comunes (retornar a Chaitén, recuperar sus estilos de vida) que surgen desde los propios vecinos; configurando así una experiencia subjetiva de pertenencia a una colectividad mayor, formando parte de una red de relaciones de apoyo mutuo en la que se puede confiar, transformándose en un nosotros, creándose un sentimiento de pertenencia para los miembros de una comunidad, de ser importantes para los demás y para el grupo, y una creencia compartida en que las necesidades de los miembros serán atendidas a través del compromiso de estar juntos y de tomar conciencia de sus problemáticas sociales; como puede observarse en el siguiente relato:

Nos unió el volcán. Después del volcán, llegamos acá, y nunca dijimos 'nos vamos'. No, cada uno llegamos solos, que es el Antonio $^{7}$ de la radio, el Lorenzo, la Ignacia, la Claudita, y así, vamos llegando y nos vamos uniendo, y 12 personas solas en un pueblo, donde no hay luz, no hay nada, y fuimos viendo después, viendo cómo podíamos salvar Chaitén, y empezar a pensar todos los días. Nos quedamos, nos quedamos y nos quedamos y nunca... yo no entré pensando que me iba a quedar, y menos que me iba a quedar 6 meses. No, me quedé, me quedé y nos quedamos, y a todos nos pasó lo mismo (Entrevista Dirigente Social 1).

El que... es algo que no me canso de repetirlo nunca, estando afuera aprendimos que nosotros realmente teníamos, no sé, apego el uno del otro (...) porque nos dimos cuenta que éramos una comunidad que realmente estábamos afiatados y que nos necesitábamos y eso, no me gustaría que se perdiera lo que descubrimos estando afuera (Entrevista Dirigente Social 3).

En este sentido, y como se ha desarrollado en otros análisis del caso (Ugarte, 2014), se puede sostener que en Chaitén el actor social emerge en tanto sujeto político, en la medida que busca romper, desde la igualdad, con las jerarquías y distinciones establecidas por la institucionalidad y lucha por construirse a sí mismo desde nuevas significaciones que le permitan transformar su realidad; los chaiteninos que han retornado buscan establecer un mayor control sobre sus vidas, transformando las relaciones de poder que se han establecido en el territorio a partir del desastre vivido, y para ello se han servido de la asociación, al reconocer elementos comunes tanto en sus historias de agravio y desgarro identitario, como en sus representaciones del orden social. Y si bien en este caso no buscan un cambio radical en el orden social, si se movilizan para hacer transformaciones en su entorno más próximo, para ganar mayor control sobre las decisiones que se toman en lo que consideran su territorio (Ugarte, 2014, p. 74).

No obstante este sentido de unidad y de acción colectiva, actualmente también se advierten elementos que dificultan la construcción de una identidad colectiva, cuestión que es observada en otras situaciones de vulnerabilidad, ante las desigualdades que se producen al interior de las poblaciones afectadas, a partir de las diferencias en el acceso a recursos y servicios. En el caso de

7 Los nombres han sido cambiados para proteger la identidad de los sujetos. 
Chaitén -durante el periodo de trabajo de campo-, aún pudimos observar fuertes diferencias en el acceso a servicios por parte de la zona norte $y$ sur de la localidad, lo cual era percibido como un elemento de distinción y conflicto

\section{$P$ : ¿Usted cree que la gente de Chaitén} está dividida o unida?

$R$ : en este momento si está dividida, no es por mejorar el ambiente pero si está divida.

P: Pero cada día más o cada día menos, se viene dividiendo y viene creciendo la división o se va achicando, no se sabe.

$R$ : no se sabe porque una por ejemplo cuanto se cita a reunirse toda la gente, la gente de abajo no viene, entonces después se quejan de que no tienen las mismas, los mismos beneficios que se tiene acá. Pero porque si los citan para que se junten para algo positivo, la gente porque no acude $y$ porque no acude porque quiere que las cosas se hagan allá abajo, pero si ellos no vienen a plantea sus asuntos de que las cosas se hagan igual allá como acá, imposible que el resto de gente sepa. Entonces mire la verdad es que hay ratos que uno no entiende, como que no los entiende, porque si estamos todos en un mismo, no tendría por qué haber desunión y sobre todo que hubimos pocos ahora, no es como antes y los pocos que hubimos deberíamos tener fuerzas, unir fuerzas para luchar para por los mismo ideales, de repente de muchas cosas.

$P$ : estas divisiones aparecieron después de la erupción volcánica, o antes ya existían

$R$ : si, habian antes pero no eran muy notorias ahora como más por el hecho de que la gente de abajo, como le digo, no tiene el servicio completo como esta acá arriba. (Entrevista Dirigente Social 5).

Exactamente, porque nunca se estandarizó, ese fue el problema. El problema es que esa asi como tenemos hoy día que no hay coordinación ni planificación en el retorno, en ese momento no hubo estandarización de lo que se iba a dar. Entonces se dio al evacuado, al desplazado, al que estaba de paso, al que tenía una casa y se había ido hace cinco años. Sí, entonces eso generó animosidad. La gente que se molestó, "por qué le dan así (Entrevista Representante Gobierno Local 2)

Otro elemento que ha impactado la convivencia, según algunos entrevistados/as, se relaciona con lo que consideran como influencia de la experiencia vivida fuera de Chaitén durante el periodo de desplazamiento. Dicha etapa habría impactado en nuevas formas de convivencia, adhesión a valores distintos, que habrian transformado, en cierta medida, la identidad chaitenina:

E: ¿Y también las personas comentan que, o piensan que se podría hacer algo por recuperar, así como cuando tú dices "este es mi sueño personal", es como sueño común tú crees, como de los vecinos, así apelando más a tu conocimiento de los vecinos?

$R$ : Ah...yo creo que no fíjate (suspira). Yo creo que no. Yo creo que es, es parte de los costos de reconstruir Chaitén, que tiene que ver con este distanciamiento, porque nosotros trajimos conductas de ciudades grandes acá, cachai, conductas que tienen que ver con encerrarse, con esta capacidad de nuclearización, cachai, donde "yo y mi grupo familiar no más". Pero esta necesidad de...individualismo de las ciudades grandes, consumo, cachai, de generar más status, dinero. Esas cosas mercantilistas, que en realidad pasa en todo el país, y que no pasaba en Chaitén. Y se está instalando, precisamente en la gente que está retornando, cachai. Yo no digo que sea malo, pero es parte de una conducta que tenemos. (Entrevista Representante Gobierno Local 1)

\section{Identidad Territorial y disputa por el espacio}

Asumiendo que el espacio no da cuenta tan sólo del escenario en el que se desenvuelven los actores sociales, sino que por el contrario es un elemento central en la constitución de éstos y de sus identidades (Arteaga, 2003), es relevante analizar los elementos de identidad territorial que aparecen 
en los chaiteninos en relación a la experiencia de desastre socionatural vivida. De este modo, el rol que juega el espacio en la construcción de identidades sociales se basa en el supuesto de que es posible encontrar procesos de identificación con el espacio, los que pueden ser tomados como categorías sociales de diferenciación frente a los demás y de afirmación del yo, que generan conductas de apego y apropiación hacia lugares concretos del espacio (Pol, 1996; Valera \& Pol, 1994). Por lo tanto, el hecho de compartir un espacio resulta clave en la construcción, permanencia, reproducción y reconocimiento del grupo, en tanto que establece límites específicos y marca la diferencia entre lo colectivo y los otros. Estas marcas, a su vez, se reflejan en aspectos concretos y simbólicos, constituyendo una espacialidad propia de determinada identidad social (Arteaga, 2003).

Sobre la base de la relación sociedadespacio, se da lugar a la noción de construcción social de la realidad a partir del espacio. Hiernaux (2007) se refiere a la construcción social del lugar, señalando que la articulación de lo subjetivo y lo objetivo de la espacialidad, construye socialmente los lugares. Esta relación la establece también Orella (2010), al señalar que del lugar se extraen elementos que conforman una identidad individual y colectiva; al mismo tiempo, estos elementos (que pueden proceder de condiciones materiales, geográficas o históricas), presentan en común la carga de significado asignado por quienes los habitan.

En relación a lo anterior, es posible identificar, en el relato de los entrevistados, formas particulares de relacionarse con su entorno, las que se materializan en formas de habitar el territorio. La percepción del espacio y las relaciones que con él se establecen, influyen en los procesos de adaptación durante el desplazamiento y en la necesidad, manifestada por los entrevistados, del retorno y reconstrucción, necesidad de volver a un territorio que consideran propio:

Porque Chaitén si bien es un pueblo joven, todo lo que tú quieras, hay mucha gente que tiene sus raíces acá, han vivido acá toda su vida, o sea no conocen otra cosa, ahora han salido afuera y afuera se han encontrado con un mundo que no es acogedor, no es acogedor como en este pueblo, tú en este pueblo tú dejas las puertas abiertas de tu casa y no pasa nada (Entrevista Grupal 4).

(...) Si incluso en Palena no nos adaptábamos que es parecido acá y era por el espacio, por la amplitud, Palena está más encajonado, imaginate lo que estamos hablando (Entrevista Representante Gobierno Local 3).

Las relaciones que se establecen en los territorios entre los distintos actores que participan de él y que ejercen poder sobre él son altamente complejas, cambiantes, de competencia y de permanente disputa entre actores que mantengan derechos, soberanía, atribuciones y potestad sobre el mismo espacio. Según Perló y Moya (2003) estas relaciones generalmente son de dominio y de control; sin embargo, según los autores, estas relaciones también pueden orientarse a la buena convivencia, negociación y cooperación; configurándose en ciclos que contendrían periodos de estabilidad y convivencia, así como de extremo conflicto, según los factores históricos, jurídicos, políticos y coyunturales del caso.

Las lógicas de funcionamiento de los actores del territorio, en el caso de Chaitén, principalmente de la ciudadanía, gobierno local y gobierno central, muchas veces son contrapuestas, pues expresan ideologías, proyectos políticos o intereses divergentes entre los poderes, y por ende, se produce el conflicto por la soberanía. Siguiendo a los autores antes señalados (Perló \& Moya, 2003), este tipo de relaciones se exacerban y pueden llegar a puntos de inflexión en los casos en que dos o más poderes comparten un territorio relativamente reducido, cuando se presenta una crisis política a nivel nacional, o cuando se presenta alguna problemática aguda como una situación de ingobernabilidad o una catástrofe natural, como es el caso de Chaitén. Aquí, el conflicto se produce principalmente por el ejercicio de la gobernabilidad y el dominio simbólico, por la soberanía territorial:

(...) tiene que ver con un tema de lucha, tienequevercon un tema de quiénes estuvieron aquí a motor, sin agua, sin luz, cachai. Tiene que ver con un tema de comodidad, de 
calidad de vida, cachai. Yo creo que por ahí va el tema, el tema de que no basta decir: soy chaitenino porque fui evacuado y volví a Chaitén en 2008'; 'Soy chaitenino porque ayudé a recuperar el puebló. Tiene que ver un poco con ese discurso, cachai. (...) tiene que ver con un tema de recuperación y con un tema de identidad, cachai, con un tema de lucha (Entrevista Representante Gobierno Local 2).

En este sentido, Milton Santos ha planteado:

El espacio geográfico, su materialidad, constituye a la vez una condición y un limite para la acción, una estructura de control así como una invitación a la acción. No es posible hacer nada sin que nuestra acción se relacione con los objetos materiales que nos rodean (Milton Santos, 1999, p. 257 en Arteaga, 2003).

Desde allí es posible entonces identificar relaciones entre sujetos y espacios en el contexto de una disputa por la apropiación material y simbólica del mismo, la lucha con otros actores por el control del territorio y la construcción cotidiana del entorno habitacional y comunitario (Arteaga, 2003). En línea con esta idea, para Safa, lo que estaría en juego en el conflicto son los derechos de los ciudadanos y sus límites, y la capacidad del Estado y sus obligaciones (Safa, 2003, p. 263); los conflictos del territorio entonces serían conflictos de interés, pero fundamentalmente de lucha por la gestión del territorio. Como se advierte en el caso de Chaitén, al igual que en otros casos, en esta localidad se han buscado solucionar principalmente problemas relacionados con la vivienda y con las condiciones generales de la calidad de vida, permitiendo a su vez la formación de diversas asociaciones vecinales (Safa, 2003; Arzaluz, 2003), como el Comité de Vivienda Chaitén Sur, el Comité de Vivienda Santa Bárbara, el Comité de Desplazados de Chaitén, y grupos de Adultos Mayores y Clubes Deportivos

8 Al respecto, existen estudios acerca del impacto diferenciado de la percepción de riesgo de los desastres desde la perspectiva de las identidades de género (Morioka, 2014), así también, hay análisis acerca del impacto diferenciado
(Marchant, 2010).

Reorientaciones en los proyectos individuales

Como hemos señalado, el proceso de construcción de identidades -individuales y colectivas- se da en un contexto social y es un proceso que contiene elementos del orden de lo individual, lo biográfico, así como de lo estructural. En ese marco, los acontecimientos que se desarrollan en un contexto de desastre, inciden de diversas maneras en las poblaciones afectadas ${ }^{8}$. En este caso es posible advertir algunas modalidades en que la construcción de las identidades individuales y los proyectos de vida, sufrieron transformaciones a partir de lo ocurrido con la erupción del Volcán Chaitén, así como el proceso de evacuación, retorno y reconstrucción.

Dentro de este aspecto, es posible distinguir las maneras en que las y los entrevistados advierten amenazas a la construcción de identidad y la viabilidad del proyecto de vida individual en Chaitén. Al respecto, se advierten casos de familias que cambiaron y reorientaron sus proyectos de vida y su vinculación territorial con Chaitén, a partir de las nuevas posibilidades y oportunidades que vislumbraron en las localidades donde fueron desplazadas.

...incluso más yo creo con el tiempo hay gente que ya no va a volver más, ya no vuelve, porque motivo, porque los chicos van haciendo familia también, sí que es lo que es familia: un amigo, su polola, ese contacto con el territorio, si son 4 años, un chico que tenía 12 años hoy día tiene $16 \mathrm{pa}^{-}$17. Yo incluso en un momento cuando no había ni luz ni agua, yo decía tú creí que un chico que lleva dos años afuera quiere volver a Chaitén si no está el cómo se llama, el Internet, comunicaciones, colegio con equipamiento... es difícil, muy difícil. De repente asusta así como que este sea un pueblo viejo, porque si los que estaban ligados a la historia de este cuento quieren volver. (Entrevista Dirigente

entre hombres y mujeres respecto a los efectos de los desastres y el uso de normas culturales que han sustentado la capacidad de reconstrucción de las vidas de mujeres frente a los desastres (Chu-Li, 2014). 
Social 5).

Por otra parte, casi de manera antagónica, existen algunas personas y familias que a partir del evento del volcán Chaitén y los sucesos ocurridos con posterioridad, reorientaron sus proyectos de vida, sus aspiraciones. Dentro de este grupo, hay quienes se acomodaron a las nuevas circunstancias, de manera más natural y como una forma de enfrentar los cambios y seguir adelante. En dicho marco, algunas familias se reinventaron, reorientando sus estrategias y sus proyectos de vida, a partir, por ejemplo, del inicio de nuevas actividades económicas.

P.: es que empezamos hace poco, creo que en octubre, ¿el mes pasado? No, octubre, septiembre ¿agosto? En agosto, en agosto empezamos asi como probando, un domingo al mes, eh...

E.: y ¿qué hacian?

$P .:$ vendemos... no se po' ropa nueva, ropa usada, como yo tenía las cosas de mi carrito de ahí...

E.: y ¿dónde se ponen?

P.: antes, en el colegio que estaba ahí, y después por un tema de espacio, que no era muy bonito adentro, que está muy maltratado, eh... buscamos la sede social de la villa, y ahi estamos, el domingo pasado tuvimos la feria, y el antepasado también, ahora vamos hacer una feria navideña que va a ser en diciembre, sábado y domingo en las tardes, y ahí nos estamos organizando así de a poquito.

E.: ¿y va harta gente?

P.: si... es que no hay, eh... yo les digo a las chicas "acá no hay nada que uno diga, vamos a tal parte, no se po', por último a cachurear, aunque no compren nada", pero el tema de decir vamos a tal parte, de salir, porque aqui no hay mall, no hay supermercado, no hay nada asi como que uno diga "vamos a vitrinear". No se puede, entonces una alternativa más que se dé y un fin de semana, yo lo encontré bueno, aparte que como estuve en Achao, en Achao se hacía feria lunes, miércoles y viernes (Entrevista Apoderado Escuela).
La posibilidad de iniciar nuevos proyectos y la reinvención del proyecto de vida, también se desarrolló a partir de las condiciones extremas que debieron vivir algunos desplazados, los que frente al desarraigo y la pérdida de fuentes laborales, construyeron nuevos proyectos individuales $y$ colectivos fuera de Chaitén. Es el caso de un grupo de profesores que frente a la pérdida de empleo y la falta de reinserción laboral, optaron finalmente por iniciar un proyecto educativo en Puerto Montt.

Eso se dio porque, en su minuto, luego de la erupción del volcán, los docentes de la comuna quedamos sin nuestra fuente laboral, quedamos a la deriva, insertos en diferentes partes del país. Muchos nos concentramos acá y en Chiloé, Chiloé también es una gran parte de docentes y gente de Chaitén y bueno, nosotras, entre algunas más conocidas de repente era difícil que nos insertaran, nosotros estuvimos trabajando harto en el tema, cómo se dice, estuvimos tratando que el gobierno nos insertara en los colegios, pero por nuestras leyes era imposible, no es tan fácil, ni siquiera frente a esta emergencia, no hubo posibilidades (Entrevista Docente Escuela).

Reflexiones finales

A lo largo del trabajo hemos hecho referencia a la relación que se produce entre la ocurrencia de un desastre socionatural -en este caso la erupción volcánica en la localidad de Chaitén- y la dinámica de construcción identitaria. A partir del análisis de los relatos, fue posible advertir las diferentes formas en que la destrucción material a partir del evento, tuvo consecuencias en términos de la identificación de los habitantes con su territorio, su historia, su calidad de vida, sus proyectos. Dicha cuestión es relevante en la medida que la materialidad y el ámbito territorial, sustentan el arraigo y la construcción de identidades colectivas. La historia del poblamiento, asimismo, refuerzan el sentido de pertenencia por una parte, a la vez que la sensación de indeterminación y vulnerabilidad. Ello se refleja en la forma y el contenido de las narraciones, las cuales en ocasiones son nostálgicas y apegadas a una historia pasada que se siente perdida hoy día. 
A partir de la erupción y lo ocurrido posteriormente, gatillado asimismo por el dispositivo de la entrevista, surge un proceso reflexivo acerca del pasado, el presente $y$, en ocasiones el futuro, cuestión que se pone de relieve frente a un desastre de la magnitud que se vivió en la localidad. Un desastre de este tipo, hace emerger sentimientos, pensamientos, reflexiones y acciones nuevas, en términos individuales, familiares $y$ comunitarios, lo que da cuenta de procesos de cambio en las dinámicas identitarias a distintos niveles. Dicho proceso de reflexión, dio paso en este caso -como en otros similares- a acciones colectivas relativamente espontáneas, orientadas a la reconstrucción material y simbólica de la comunidad, no excentas, por cierto, de conflictos al interior de la localidad y con los distintos actores que se desenvuelven en el territorio.

Dichos elementos de reflexión, de acción, así como la historia de la vida construida previamente al desastre en Chaitén, permiten no obstante, dotar de sentido el retorno y el futuro de la localidad en la mayor parte de los casos; en otros, sin embargo, el proyecto de vida se traslada a localidades alejadas. A pesar de dichos proyectos, las consecuencias negativas en términos psicosociales no pueden ser soslayadas.

Como señalamos al inicio del texto, la dimensión identitaria es clave en la construcción del sentido colectivo y de comunidad, así como en la constitución personal. En dicho contexto, es relevante conocer $y$ atender a las alteraciones que en dicho proceso puedan darse en un evento socionatural, cuestión relativamente permanente en la historia de nuestro territorio.

\section{BIBLIOGRAFÍA}

Arteaga Aguirre, C. (2003). Espacio local, identidades y acción colectiva en la ciudad de México. El caso de Ajusco Medio en la delegación Tlalpan. En K. Ramírez (Ed.), Espacio público y reconstrucción ciudadana (pp. 365-392). México: FLACSO.

Arzaluz Solano, S. (2003). Ciudadanía y territorio en el estado de México: La experiencia de los consejos de participación ciudadana en Ecatepec, Tialnepantla y Nezahualcóyotl. En K. Ramírez (Ed.), Espacio público y reconstrucción ciudadana (pp. 393-434). México: FLACSO.

Bengoa Cabello, J. (1996). La comunidad perdida. Ensayos sobre identidad y cultura: lo desafíos de la modernización en Chile. Santiago de Chile: Ediciones Sur.

Berger, P. L., \& Luckmann, T. (1999). La construcción social de la realidad. Argentina: Amorrortu.

Cardona Arboleda, O. D. (2001). El impacto económico de los desastres: esfuerzos de mediciones existentes y propuesta alternativa. Unidad Ejecutora sectorial del subprograma de prevención de desastres. Secretariado técnico de la presidencia de la República Dominicana y Banco Internacional de Desarrollo.

CEPAL (2010). Evaluaciones económicas y Sociales de desastres en Haití 2004-2008. CEPAL.

Cutter, S. L., Boruff, B. J., \& Shirley, W. L. (2003). Social vulnerability to environmental hazards. Social Science Quarterly, 84, 242-261.

Chu-Li, J. L., \& Faye, M. (2014). Resilience in a cultural context: Taiwanese female earthquake survivors. Qualitative Social Work, 13(2), 288-303. doi: 10.1177/1473325012470694

Giménez Montiel, G. (2000). Materiales para una teoría de las identidades sociales. En J. M. Valenzuela (Ed.). Decadencia y auge de la identidades. Cultura Nacional, identidad cultural y modernización. México: El colegio de la Frontera Norte. Plaza y Valdés.

Hiernaux-Nicolas, D. A. J. G. (2007). Los imaginarios urbanos: de la teoría y los aterrizajes en los estudios urbanos. EURE, 33(99), 17-30.

Letelier Troncoso, F., \& Boyco Chioino, P. (2010). Talca posterremoto: una ciudad en disputa. Santiago de Chile: Ediciones SUR.

Marchant Espinoza, J. P. (2010). Documento Proyecto de práctica profesional "Lágrimas de ceniza. Estudio cualitativo sobre la experiencia de desplazamiento de los habitantes de Chaitén, asentados en las ciudades de la Isla de Chiloé y Puerto Montt". Santiago de Chile: ONEMI.

Maskrey, A. (1993). Los desastres no son naturales. Bogotá: La Red-Tercer Mundo editores.

Meli, R. D., Beltrán, D., \& Santa Cruz, S. (2005). El impacto de los desastres naturales en el desarrollo: documento metodológico básico para estudios nacionales de caso. Naciones Unidas. Comisión Económica para América Latina y el Caribe-CEPAL.

Mejía Navarrete, J. (2000). El muestreo en la Investigación Cualitativa. Revista Investigaciones Sociales, 4(5), 165-180.

Murcia Peña, N., \& Jaramillo Echeverri, L. G. (2000). La complementariedad etnográfica. Investigación 
Cualitativa. Una guía posible abordar estudios sociales. Armenia (Colombia): Kinesis.

Morioka, R. (2014). Gender difference in the health risk perception of radiation from Fukushima in Japan: the role of hegemonic masculinity. Social Science \& Medicine, 107, 105-112.

Oficina Nacional de Emergencia del Ministerio del Interior ONEMI (2008a). Informe N 243: Traslado preventivo de habitantes de la comuna de Chaitén. Recuperado de http://www.redhum.org/archivos/pdf/ID_2181_ Redhum-CL-Informe_No_243__Volcan_ChaitenONEMI-20080504.pdf

(2008b) Informe $N^{\circ}$ 245: 3900 personas evacuadas en Chaitén en las últimas horas. Recuperado de http:// www.redhum.org/archivos/pdf/ID_2184_RedhumCL-Informe_No_245_3.900_personas_evacuadas_ en_Chaiten_en_las_ultimas_horas-ONEMI-20080504. pdf

Orella Unzue, J. L. (2010). Geohistoria. Lurralde: inves.espac. 33, 233-310. Recuperado de http://www.ingeba.org/ lurralde/lurranet/lur33/33orellaateneo/33orelateneo. pdf

Perló Cohen, M., \& Moya, A. (2003). Dos poderes, un solo territorio: ¿Conflicto o cooperación? Un análisis histórico de las relaciones entre los poderes central y local en la ciudad de México de 1325 a 2002. En Ramírez Kuri, P. (coord.), Espacio público y reconstrucción ciudadana. (173-210) México: FLACSO.

Pol Urrutia, E. (1996). La apropiación del espacio. En L. Iñiguez \& E. Pol (Eds.), Cognición, representación y apropiación del espacio. Barcelona: Universidad de Barcelona.

Revet, S. (2011). Penser et affronter les désastres: un panorama des recherches en sciences sociales et des politiques internationales. Critique internationale, 3(52), $157-$ 173.

Safa Barraza, P. (2003). La emergencia de ciudadanías y de proyectos de ciudad: Los nuevos retos de la planeación urbana. En K. Ramírez (Ed.), Espacio Público y Reconstrucción Ciudadana, (pp. 253-270). México: FLACSO

Sánchez-Vidal, A. (2001). Medida y estructura interna del sentimiento de comunidad: Un estudio empírico. Revista de Psicología Social, 16, 157-175.

Strauss, A. L., \& Corbin, J. (2002). Bases de la investigación cualitativa. Técnicas y procedimientos para desarrollar la teoría fundamentada. Medellin: Antioquía.

Tejerina Montaña, B. (2005). Movimientos sociales, espacio público y ciudadanía: los caminos de la Utopía. Revista Crítica de Ciências Sociais, 72, 67-97.

Ugarte Caviedes, A. M. (2014). Sujetos politicos en contextos de desastre socionatural: el caso de Chaitén. (Tesis para optar al grado de Magister en Ciencias Sociales, mención Sociología de la Modernización). Facultad de Ciencias Sociales, Universidad de Chile, Santiago de Chile.

Valenzuela, J. (2000). Decadencia y auge de las identidades. México: Colegio La Frontera Norte. Plaza y Valdés.

Valera Pertegas, S., \& Pol Urrutia, E. (1994). El concepto de identidad social urbana: Una aproximación entre la psicología social y la psicología ambiental. Anuario de Psicología, 62, 5-24.

Weichselgartner, J. (2001). Disaster Mitigation: The Concept of Vulnerability Revisited. Disaster Prevention and Management, 10(2), 85-94.

Wilches-Chaux, G. (1993). La vulnerabilidad global, En A. Maskrey (Ed.), Los desastres no son naturales, Bogotá: La Red-Tercer Mundo editores. 